\title{
Androgen Receptor and PIM1 Expression in Tumor Tissue of Patients With Triple-negative Breast Cancer
}

\author{
ALIKI NTZIFA $^{1}$, ARETI STRATI ${ }^{1}$, GEORGIA-ANGELIKI KOLIOU ${ }^{2}$, FLORA ZAGOURI $^{3}$, \\ DIMITRIOS PECTASIDES ${ }^{4}$, GEORGE PENTHEROUDAKIS ${ }^{5,6}$, CHRISTOS CHRISTODOULOU $^{7}$, HELEN GOGAS $^{8}$, \\ CHRISTINA MAGKOU ${ }^{9}$, CONSTANTINA PETRAKI ${ }^{10}$, PARIS KOSMIDIS ${ }^{11}$, GERASIMOS ARAVANTINOS ${ }^{12}$, \\ VASSILIKI KOTOULA ${ }^{13,14}$, GEORGE FOUNTZILAS ${ }^{14,15,16}$ and EVI LIANIDOU ${ }^{1}$ \\ ${ }^{1}$ Analysis of Circulating Tumor Cells Laboratory, Laboratory of Analytical Chemistry, \\ Department of Chemistry, University of Athens, Athens, Greece; \\ ${ }^{2}$ Section of Biostatistics, Hellenic Cooperative Oncology Group, Data Office, Athens, Greece; \\ ${ }^{3}$ Department of Clinical Therapeutics, Alexandra Hospital, \\ National and Kapodistrian University of Athens School of Medicine, Athens, Greece; \\ ${ }^{4}$ Oncology Section, Second Department of Internal Medicine, Hippokration Hospital, Athens, Greece; \\ ${ }^{5}$ Department of Medical Oncology, Medical School, University of Ioannina, Ioannina, Greece; \\ ${ }^{6}$ Society for Study of Clonal Heterogeneity of Neoplasia (EMEKEN), Ioannina, Greece; \\ ${ }^{7}$ Second Department of Medical Oncology, Metropolitan Hospital, Piraeus, Greece; \\ ${ }^{8}$ First Department of Medicine, Laiko General Hospital, \\ National and Kapodistrian University of Athens School of Medicine, Athens, Greece; \\ ${ }^{9}$ Pathology Department, Evangelismos Hospital, Athens, Greece; \\ ${ }^{10}$ Department of Pathology, Metropolitan Hospital, Piraeus, Greece; \\ ${ }^{11}$ Second Department of Medical Oncology, Hygeia Hospital, Athens, Greece; \\ ${ }^{12}$ Second Department of Medical Oncology, Agii Anargiri Cancer Hospital, Athens, Greece; \\ ${ }^{13}$ Department of Pathology, Aristotle University of Thessaloniki, \\ School of Health Sciences, Faculty of Medicine, Thessaloniki, Greece; \\ ${ }^{14}$ Laboratory of Molecular Oncology, Hellenic Foundation for Cancer \\ Research/Aristotle University of Thessaloniki, Thessaloniki, Greece; \\ ${ }^{15}$ Aristotle University of Thessaloniki, Thessaloniki, Greece; \\ ${ }^{16}$ German Oncology Center, Limassol, Cyprus
}

\begin{abstract}
Background/Aim: Effective targeted therapies for triple-negative breast cancer (TNBC) are limited. In a subset of $T N B C$, androgen receptor $(A R)$ plays an important role, while the human proviral integration site for Moloney murine leukemia virus-1 (PIM1) overexpression is also implicated. PIMI kinases phosphorylate AR, thus regulating
\end{abstract}

This article is freely accessible online.

Correspondence to: Evi Lianidou, Ph.D., Professor of Analytical Chemistry - Clinical Chemistry, Laboratory of Analytical Chemistry, Analysis of Circulating Tumor Cells (ACTC) Laboratory, Department of Chemistry, University of Athens, Athens, Greece. E-mail: lianidou@chem.uoa.gr

Key Words: Triple-negative breast cancer, androgen receptor, PIM1, RT-qPCR. its transcriptional activity, regardless of the presence or not of androgens. We evaluated the expression of AR and PIMI and their prognostic significance in TNBC. Materials and Methods: AR and PIM1 transcripts were quantified by quantitative reverse transcription polymerase chain reaction in formalin-fixed paraffin-embedded tumor from 141 patients with TNBC. Results: AR was expressed in 38.3\%, PIM1 in $10.6 \%$, while co-expression of AR and PIM1 was detected in 7/141 cases (5.0\%). No prognostic significance of AR or PIM1 was reached for overall or disease-free survival. Conclusion: Co-expression of AR and PIM1 exists in only in a small percentage of patients with TNBC. The implications of this finding in the therapeutic management of patients with TNBC should be investigated in larger patient cohorts.

Triple-negative breast cancer (TNBC) accounts for the 15$20 \%$ of breast cancer cases and is devoid of the expression of estrogen (ER) and progesterone receptors, and of human 
epidermal growth factor receptor 2 (HER2) protein overexpression or amplification (1). It exhibits the poorest prognosis among other breast cancer subtypes, it is usually basal-like and of higher grade. These features combined with the lack of the common breast cancer targeted biomarkers render it a highly aggressive breast cancer subtype (2). Lehmann et al. were the first to classify TNBC into seven stable subtypes, indicating the high molecular heterogeneity of the disease (3).

Neoadjuvant chemotherapy is the current mainstay treatment option for patients with TNBC who intriguingly achieve improved pathological complete response compared to other breast cancer subtypes, in spite of its unfavorable prognosis (4, 5). However, disease in only a small subset of these patients is chemosensitive, while the majority are susceptible to treatment resistance (6). There are not only several established therapy protocols but also many ongoing clinical trials examining the efficacy of new targeted therapies or the combination of different regimens, based on distinct molecular alterations in TNBC (7). Nevertheless, the aggressive profile of TNBC and its heterogenous molecular landscape further underpin the necessity for determining new biomarkers that might enable selection of patients for targeted therapies.

Androgen receptor (AR) signaling plays an important role in breast cancer biology, albeit complicated due to the nuanced differences exhibited between AR-positive breast cancer in relation to the co-existence of other receptors (8). During the last years, the luminal androgen receptor subtype, which is characterized by the unique presence of AR, is in the forefront of research interest. This subtype is associated with better prognosis among other TNBC subtypes, is less responsive to chemotherapeutic regimens and presents lower pathological complete response after neoadjuvant treatment (9). The oncogenic functional role of AR in luminal androgen receptor TNBC is through maintaining cell proliferation (10). The prognostic role of AR in TNBC still remains controversial (11). A meta-analysis supports the favorable prognosis of AR-positive TNBC (12) in contrast to studies that support the opposite $(13,14)$, while others did not associate AR expression with prognosis at all $(15,16)$. Notwithstanding the equivocal results for the impact of AR expression on survival outcomes, targeted therapy for ARpositive TNBC may be beneficial. In the light of the prognostic and predictive role of AR in prostate cancer $(\mathrm{PCa})$ and the availability of anti-androgen directed therapies, previous and ongoing clinical trials tested the efficacy of these drugs in AR-positive TNBC and presented some promising results $(8,17)$. In this rapidly evolving field of $A R$ study, many other therapeutic targets involved in the AR pathway are also being examined (7).

The human proviral integration site for Moloney murine leukemia virus-1 (PIM1), a serine/threonine kinase, is normally implicated in cell-cycle progression, survival, proliferation, and apoptosis; on account of this, PIM1 plays an important role in development, progression and maintenance of tumor $(18,19)$. PIM1 kinase was first associated with murine leukemia virus (MuLV)-induced lymphomas (20) and subsequent analyses in transgenic mice revealed its oncogenic role (21). Apart from leukemia (22), its up-regulation has been extensively studied in $\mathrm{PCa}$ and in many other types of cancer as well [reviewed in (23)]. Recent studies based on the collection of published datasets from clinical cohorts confirmed a significant up-regulation of PIM1 in TNBC compared to the non-TNBC tumors and affiliated its aberrant expression with poor prognosis [reviewed in (24)]. The basal-like TNBC subtype exhibits the highest levels of PIMI expression, accompanied by copynumber gains and amplifications $(25,26)$. In vitro experiments using TNBC cell lines and xenografts showed that PIMI regulates cell proliferation and tumor growth by modulating anti-apoptotic proteins (BCL2 apoptosis regulator 2), cell-cycle proteins (p27) and the oncogene cMYC, and that PIMI inhibition increased sensitivity in patients with TNBC treated with chemotherapy $(25,26)$. Moreover, based on previous evidence on PCa, PIM1 kinases phosphorylate $\mathrm{AR}$, thus regulating its transcriptional activity, both in the presence and absence of androgens. This mechanism seems to play a crucial role during androgen deprivation therapy, and co-targeting of AR and PIM1 would exhibit improved therapeutic effects on resistant PCa (27).

In the present study, we evaluated $A R$ and PIMI expression in TNBC clinical specimens using validated RTqPCR assays $(28,29)$ and investigated their association with clinicopathological parameters and prognostic significance in terms of overall (OS) and disease-free (DFS) survival.

\section{Materials and Methods}

Patients. RNA was isolated from formalin-fixed paraffin-embedded (FFPE) tumor samples from 194 women with TNBC, and after evaluation of RNA quality, 141 such samples were finally included in the current analysis. Overall, 134/141 (95\%) patients were treated for high-risk breast cancer in the context of Hellenic Cooperative Oncology Group's (HeCOG) adjuvant clinical trials (30-34). A total of 139 patients (98.6\%) had received adjuvant chemotherapy, whereas one patient refused to receive any treatment, and for one additional patient there was no further information regarding the type of administered therapy. The type of adjuvant chemotherapy administered is shown in Table I. Adjuvant hormonal therapy was administered in 27 patients (19.1\%). Among them, 15 patients were found to have ER/PgR-positive tumors in the local assessment based on low Histoscore (1-10) which, however, was not confirmed upon central re-evaluation of ER and PgR status. The remaining 12 patients were treated with luteinizing hormone-releasing hormone agonists only (four patients), tamoxifen only (in six), tamoxifen followed by aromatase inhibitor or aromatase inhibitor only (in one patient each) for hormonal manipulation, a practice used by some investigators at that time that has since been abandoned. The median 
Table I. Baseline patient and tumor characteristics.

\begin{tabular}{|c|c|c|}
\hline Characteristic & & Total $(\mathrm{N}=141)$ \\
\hline Age $(N=141)$, years & Median (range) & $52.5(20.9-82.7)$ \\
\hline \multirow{2}{*}{ Menopausal status $(\mathrm{N}=141), \mathrm{n}(\%)$} & Premenopausal & $65(46.1 \%)$ \\
\hline & Postmenopausal & $76(53.9 \%)$ \\
\hline \multirow[t]{6}{*}{ Histology classification $(\mathrm{N}=141), \mathrm{n}(\%)$} & Inflammatory & $1(0.71 \%)$ \\
\hline & Invasive ductal & $119(84.4 \%)$ \\
\hline & Invasive lobular & $4(2.8 \%)$ \\
\hline & Medullary with lymphocytic & $11(7.8 \%)$ \\
\hline & Mixed & $3(2.1 \%)$ \\
\hline & Other & $3(2.1 \%)$ \\
\hline \multirow[t]{4}{*}{ Histological grade $(\mathrm{N}=140), \mathrm{n}(\%)$} & 1 & $2(1.4 \%)$ \\
\hline & 2 & $23(16.4 \%)$ \\
\hline & 3 & $113(80.7 \%)$ \\
\hline & 4 & $2(1.4 \%)$ \\
\hline \multirow[t]{4}{*}{ Tumor size $(\mathrm{N}=141), \mathrm{cm}$} & Median (range) & $2.7(0.20-11.0)$ \\
\hline & $\leq 2 \mathrm{~cm}$ & $45(31.9 \%)$ \\
\hline & $2-5 \mathrm{~cm}$ & $81(57.4 \%)$ \\
\hline & $>5 \mathrm{~cm}$ & $15(10.6 \%)$ \\
\hline \multirow[t]{4}{*}{ Positive nodes $(\mathrm{N}=139), \mathrm{n}$} & Median (range) & $1.00(0.00-40.0)$ \\
\hline & 0 & $47(33.8 \%)$ \\
\hline & $1-3$ & $50(36.0 \%)$ \\
\hline & $\geq 4$ & $42(30.2 \%)$ \\
\hline \multirow[t]{5}{*}{ Type of adjuvant chemotherapy $(\mathrm{N}=139)$} & E-T-CMF & $66(47.5 \%)$ \\
\hline & ET-CMF & $22(15.8 \%)$ \\
\hline & E-CMF-wDoc & $21(15.1 \%)$ \\
\hline & E-CMF-wT & $21(15.1 \%)$ \\
\hline & Other & $9(6.5 \%)$ \\
\hline \multirow[t]{2}{*}{ Adjuvant hormonotherapy $(\mathrm{N}=141), \mathrm{n}(\%)$} & No & $114(80.9 \%)$ \\
\hline & Yes & $27(19.1 \%)$ \\
\hline \multirow[t]{2}{*}{ Adjuvant radiotherapy $(\mathrm{N}=140)$} & No & $29(20.7 \%)$ \\
\hline & Yes & $111(79.3 \%)$ \\
\hline \multirow[t]{2}{*}{ ER status (local assessment) $(\mathrm{N}=141), \mathrm{n}(\%)$} & Negative & $128(90.8 \%)$ \\
\hline & Positive & $13(9.2 \%)$ \\
\hline \multirow[t]{2}{*}{ PR status (local assessment) $(\mathrm{N}=141), \mathrm{n}(\%)$} & Negative & $126(89.4 \%)$ \\
\hline & Positive & $15(10.6 \%)$ \\
\hline \multirow[t]{2}{*}{ HER2 status (local assessment) $(\mathrm{N}=140), \mathrm{n}(\%)$} & No & $131(93.6 \%)$ \\
\hline & Yes & $9(6.4 \%)$ \\
\hline \multirow[t]{2}{*}{ Basal-like ( $\mathrm{N}=139)$} & Yes & $124(89.2 \%)$ \\
\hline & No & $15(10.8)$ \\
\hline
\end{tabular}

ER: Estrogen receptor. PR: progesterone receptor. HER2: human epidermal growth factor receptor. E-T-CMF: $110 \mathrm{mg} / \mathrm{m}^{2}$ epirubicin $q 2$ weeks $\times 3$ followed by $250 \mathrm{mg} / \mathrm{m}^{2}$ paclitaxel $q 2$ weeks $\times 3$ followed by $840 \mathrm{mg} / \mathrm{m}^{2}$ cyclophosphamide; $57 \mathrm{mg} / \mathrm{m}^{2}$ methotrexate; $840 \mathrm{mg} / \mathrm{m}^{2}$ fluorouracil (CMF) $q 2$ weeks $\times 3$. ET-CMF: $83 \mathrm{mg} / \mathrm{m}^{2}$ epirubicin $+187 \mathrm{mg} / \mathrm{m}^{2}$ paclitaxel $q 3$ weeks $\times 4$ followed by CMF $q 2$ weeks $\times 3$; E-CMF-wDoc: $110 \mathrm{mg} / \mathrm{m}^{2}$ epirubicin $q 2$ weeks $\times 3$ followed by CMF $q 2$ weeks $\times 3$ followed by weekly docetaxel $35 \mathrm{mg} / \mathrm{m}^{2} \times 9$; E-CMF-wT: $110 \mathrm{mg} / \mathrm{m}^{2}$ epirubicin $q 2$ weeks $\times 3$ followed by CMF $q 2$ weeks $\times 3$ followed by weekly $80 \mathrm{mg} / \mathrm{m}^{2}$ paclitaxel $\times 9$.

age at the time of breast cancer diagnosis was 53 (range=21-83) years. Table I summarizes the patient clinicopathological characteristics of the study population. Most patients were postmenopausal $(53.9 \%)$ at the time of diagnosis and had invasive ductal tumors (84.4\%) of higher grade. Of the 139 patients with data available for epidermal growth factor receptor and/or cytokeratin 5 protein expression, $124(89.2 \%)$ had basal-like tumors. At a median follow-up of 12 years [95\% confidence intervaI $(\mathrm{CI})=11.0-13.3$ years], a total of 50 DFS events were reported and 43 patients (30.5\%) had died, while the median OS and DFS had not yet been reached at the time of the analysis.
Informed consent was obtained from all individuals included in this study. Ethical approval: The research related to human use complied with all the relevant national regulations, institutional policies and in accordance the tenets of the Helsinki Declaration. Clinical protocols were approved by local regulatory authorities and were also included in the Australian New Zealand Clinical Trials Registry and allocated the following Registration Numbers: ACTRN12611000506998 (HE10/97), ACTRN12609001036202 (HE10/00), ACTRN1261000 0151033 (HE10/05) and ACTRN12615000161527 (HE10/08). The translational research protocol was approved by the Institutional Review Board of Papageorgiou Hospital. 
Table II. Associations between AR expression and selected clinicopathological parameters.

\begin{tabular}{|c|c|c|c|c|}
\hline & & Negative (N=87) & Positive $(\mathrm{N}=54)$ & $p$-Value \\
\hline Age, years & Median (range) & $50.0(29.0-82.7)$ & $56.2(20.9-72.2)$ & $0.067^{\mathrm{a}}$ \\
\hline \multirow[t]{4}{*}{ Tumor size, $\mathrm{cm}$} & Median (range) & $2.8(0.20-11.0)$ & $2.6(1.3-10.0)$ & $0.76^{\mathrm{a}}$ \\
\hline & $\leq 2 \mathrm{~cm}$ & $27(31.0 \%)$ & $18(33.3 \%)$ & $0.62^{\mathrm{b}}$ \\
\hline & $2-5 \mathrm{~cm}$ & $49(56.3 \%)$ & $32(59.3 \%)$ & \\
\hline & $>5 \mathrm{~cm}$ & $11(12.6 \%)$ & $4(7.4 \%)$ & \\
\hline \multirow[t]{4}{*}{ Positive nodes, $\mathrm{n}$} & Median (range) & $1.00(0.00-40.0)$ & $1.5(0.00-31.0)$ & $0.32^{\mathrm{a}}$ \\
\hline & 0 & $29(34.1 \%)$ & $18(33.3 \%)$ & $0.31^{\mathrm{b}}$ \\
\hline & $1-3$ & $34(40.0 \%)$ & $16(29.6 \%)$ & \\
\hline & $\geq 4$ & $22(25.9 \%)$ & $20(37.0 \%)$ & \\
\hline \multirow[t]{2}{*}{ Histological grade, $\mathrm{n}(\%)$} & $1-2$ & $17(19.8 \%)$ & $8(14.8 \%)$ & $0.46^{\mathrm{b}}$ \\
\hline & $3-4$ & $69(80.2 \%)$ & $46(85.2 \%)$ & \\
\hline \multirow[t]{2}{*}{ Menopausal status, n (\%) } & Postmenopausal & $40(46.0 \%)$ & $36(66.7 \%)$ & $0.017^{b}$ \\
\hline & Premenopausal & $47(54.0 \%)$ & $18(33.3 \%)$ & \\
\hline \multirow[t]{2}{*}{ Basal-like, n (\%) } & No & $7(8.1 \%)$ & $8(15.1 \%)$ & $0.20^{\mathrm{b}}$ \\
\hline & Yes & 79 (91.9\%) & $45(84.9 \%)$ & \\
\hline
\end{tabular}

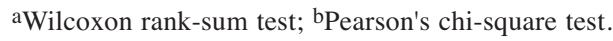

$R T-q P C R$. Total RNA was isolated from FFPE tumor samples, followed by cDNA synthesis. Beta-2 microglobulin (B2M) was used as a reference gene for quality control, to ensure the presence of amplifiable material in all samples and to avoid false-negative results, as previously described $(28,29)$. RT-qPCR assays for the quantification of $A R$ (28) and PIMI transcripts were performed as previously reported (29). To evaluate RT-qPCR specificity for each gene, we analyzed in exactly the same way matched samples from FFPE adjacent to tumor samples and ductal carcinoma in situ samples. In tumor samples, RT-qPCR data for PIM1 and AR were normalized in respect to the expression of $B 2 M$ reference gene and cut-off value was calculated by using the $2^{-\Delta \Delta C t}$ approach, as previously described by Livak and Schmittgen (35). All single RT-qPCR reactions for $A R$, $P I M 1$ and $B 2 M$ were performed in the COBAS z480 system (Roche Molecular System Inc, Pleasanton, CA, USA).

Statistical analysis. Frequencies with the corresponding percentages were used to describe categorical variables, while the median and range values were used to provide descriptive statistics of continuous variables. The chi-square and the Wilcoxon rank-sum tests were performed to evaluate the associations between AR expression and selected clinicopathological parameters. OS was defined as the time (in years) from diagnosis of breast cancer to death from any cause or last contact. Patients alive or lost to followup were censored at the date of their last contact. DFS was defined as the time from diagnosis to the first documented progression, death from any cause or last contact, whichever occurred first. Survival distributions were estimated using the Kaplan-Meier method and compared across groups with the log-rank test. The association of $A R$ and PIMI expression with progression and mortality rates was assessed with univariate Cox regression models. All tests were two-sided at significance alpha level of 5\%. No adjustment for multiple comparisons was performed since this study was exploratory and mainly hypothesis generating with predefined parameters. SAS version 9.3 (SAS Institute Inc., Cary, NC, USA) was used for statistical analysis.

\section{Results}

AR expression in TNBC samples. We evaluated the expression of $A R$ using a previously developed and validated RT-qPCR assay (28) in 141 formalin-fixed paraffin-embedded tumor samples of patients with TNBC. In total, $A R$ expression was detected in $54 / 141$ patient samples $(38.3 \%)$. The associations between selected clinicopathological parameters and $A R$ expression are presented in Table II. Patients with positive $A R$ expression were found to be less frequently of premenopausal status as compared to those with negative $A R$ expression (chisquare $p=0.017$ ). No further significant associations were observed between $A R$ expression and clinicopathological parameters.

Data on AR protein expression, as assessed by immunohistochemistry, were available for 31 patients (22.0\%). Among them, positive $A R$ gene expression was associated with positive AR protein expression (Fisher's $p=0.001)$. $A R$ mRNA expression did not show prognostic significance with respect to OS [hazard ratio (HR) for positive $A R$ expression $=0.98,95 \% \mathrm{CI}=0.53-1.82, p=0.95$; Figure 1A). Similarly, significance for $A R$ expression was not reached in terms of DFS $(\mathrm{HR}=1.07,95 \% \mathrm{CI}=0.60-1.89$, $p=0.82$; Figure $1 \mathrm{~B})$. We further evaluated the prognostic significance of $A R$ expression in the subgroup of patients with basal-like tumors $(\mathrm{N}=124)$. As in the entire cohort, $A R$ expression was not found to be prognostic among patients with basal-like tumors for either OS (HR for positive $A R$ expression $=1.03,95 \% \mathrm{CI}=0.53-1.97, p=0.94$; Figure $2 \mathrm{~A}$ ) or DFS (HR for positive $A R$ expression=1.06, 95\% CI=0.58$1.96, p=0.84$; Figure 2B). 
A

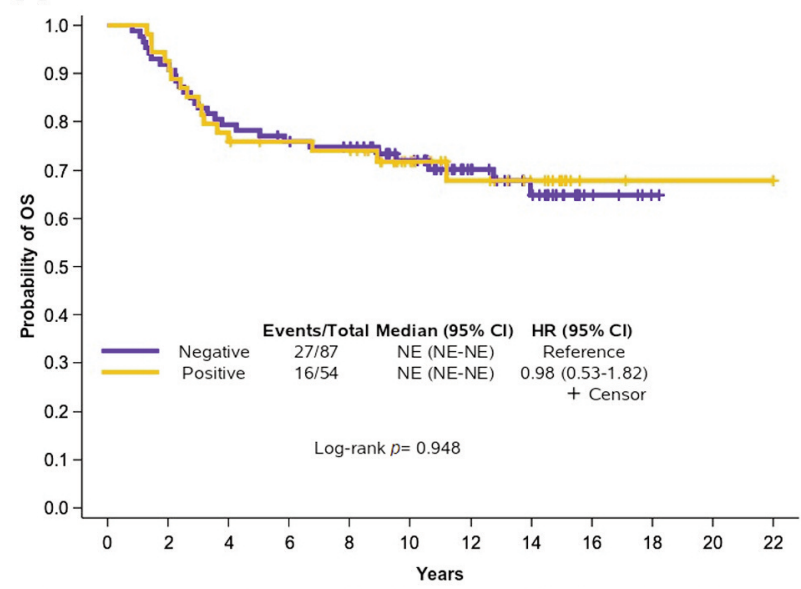

B

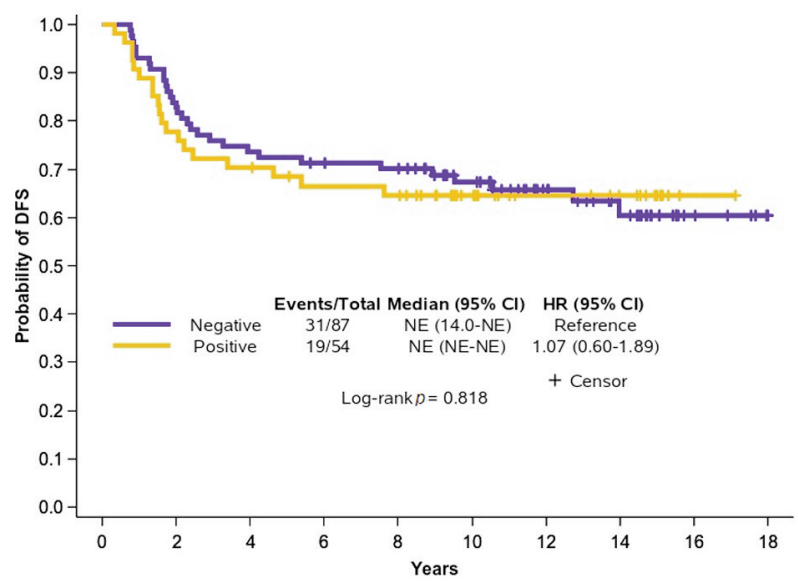

Figure 1. Kaplan-Meier curves based on androgen receptor $(A R)$ expression with respect to overall $(O S)(A)$ and disease-free $(D F S)(B)$ survival for the entire cohort. CI: Confidence intervaI; HR: hazard ratio; NE: not estimable.

PIM1 expression in TNBC samples. Most patients had tumors negative for expression of PIM1 (126 patients; $89.4 \%$ ), whereas positivity of PIMI was detected in $10.6 \%$ of the study cohort. Seven patients $(5.0 \%)$ carried tumors with positive expression of both $A R$ and PIM1. PIMI expression was not correlated with OS (HR for positive $P I M 1$ expression $=1.47,95 \% \mathrm{CI}=0.62-3.50, p=0.38$; Figure $3 \mathrm{~A})$, nor with DFS even though the corresponding HR retained the direction observed for OS, suggesting an unfavorable effect for PIMI expression ( $\mathrm{HR}=1.29,95 \%$ $\mathrm{CI}=0.55-3.02, p=0.56$; Figure $3 \mathrm{~B})$. We further evaluated the prognostic significance of PIMI expression in the subgroup of patients with basal-like tumors $(\mathrm{N}=124)$. As in the entire cohort, PIMI expression was not found to be prognostic among patients with basal-like tumors for either OS (HR for positive $P I M 1$ expression $=1.57,95 \% \mathrm{CI}=0.66-3.76, p=0.31$;
A

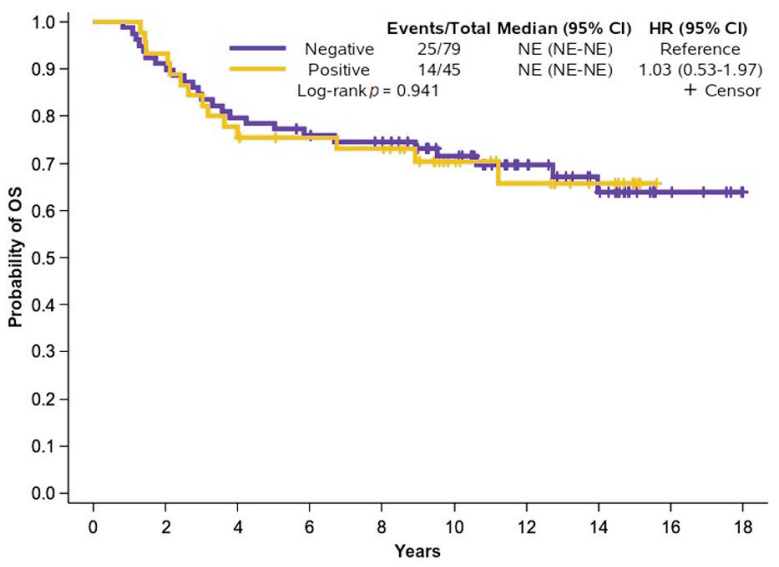

B

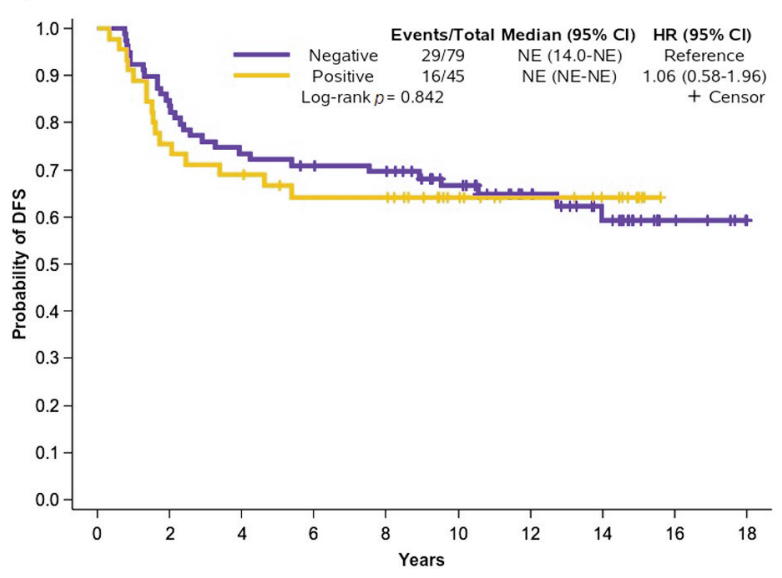

Figure 2. Kaplan-Meier curves based on androgen receptor $(A R)$ expression with respect to overall $(O S)(A)$ and disease-free $(D F S)(B)$ survival for patients with basal-like tumors. CI: Confidence intervaI; HR: hazard ratio; NE: not estimable.

Figure 4A) or DFS (HR for positive PIM1 expression=1.38, $95 \% \mathrm{CI}=0.58-3.26, p=0.46$; Figure 4B).

\section{Discussion}

TNBC heterogeneity along with its aggressive features pose a puzzling problem for the identification of new potential biomarkers. Many molecular pathways implicated in TNBC biology remain to be explored. AR signaling has already been proven to play a crucial role in a subset of TNBC (7). Therapies based on AR expression have already been tested in $\mathrm{PCa}$ and to date are also being validated in patients with TNBC. Inferentially, most TNBC therapeutic approaches refer to AR-positive TNBC cases, leaving the AR-negative subset bereft of available treatment options. Nevertheless, quadruple-negative breast cancer (QNBC) should not be 


\section{A}

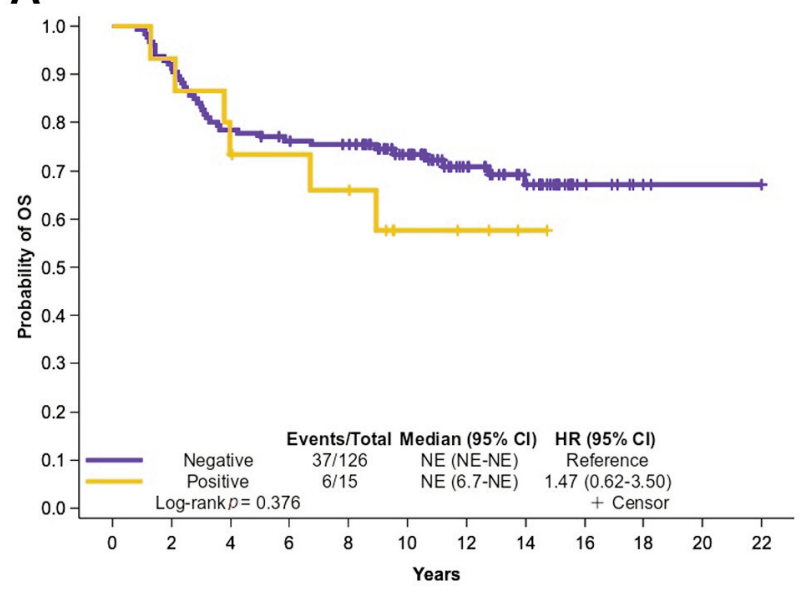

B

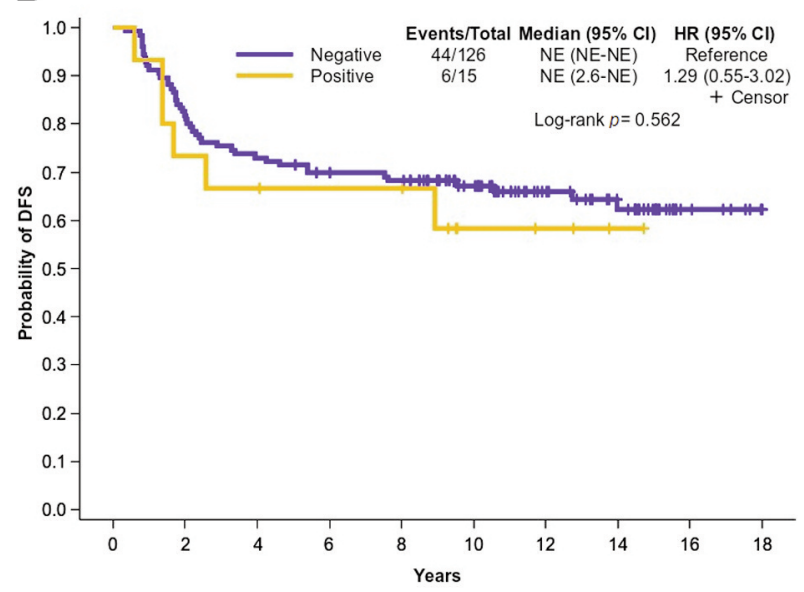

Figure 3. Kaplan-Meier curves based on human proviral integration site for Moloney murine leukemia virus-1 (PIM1) expression with respect to overall $(O S)(A)$ and disease-free $(D F S)(B)$ survival for the entire cohort. CI: Confidence intervaI; HR: hazard ratio; NE: not estimable.

disregarded as a unique molecular TNBC subtype with distinct features (36); it comprises $80 \%$ of TNBCs, mostly exhibits aggressive basal-like characteristics, and is often associated with worse prognosis in contrast to that of ARpositive TNBC $(37,38)$. In comparison to TNBC, molecular alterations between primary and metastatic paired samples during monitoring of disease revealed a more stable molecular profile of the QNBC subtype (39) and patients with QNBC seemed to be more sensitive to chemotherapy with long-term outcomes and longer DFS (37). However, treatment options are still restrictive and thus pathway proteins uniquely expressed in QNBC may serve as effective therapeutic targets (36).

Our study focused on the mRNA levels of $A R$ in a cohort of 141 patients with early-stage TNBC. According to our results, $38.3 \%$ of TNBC cases were classified as AR-
A

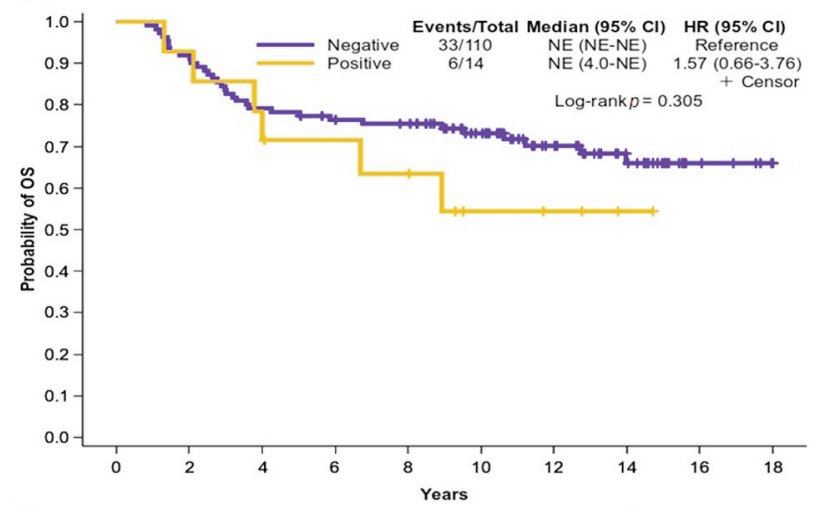

B

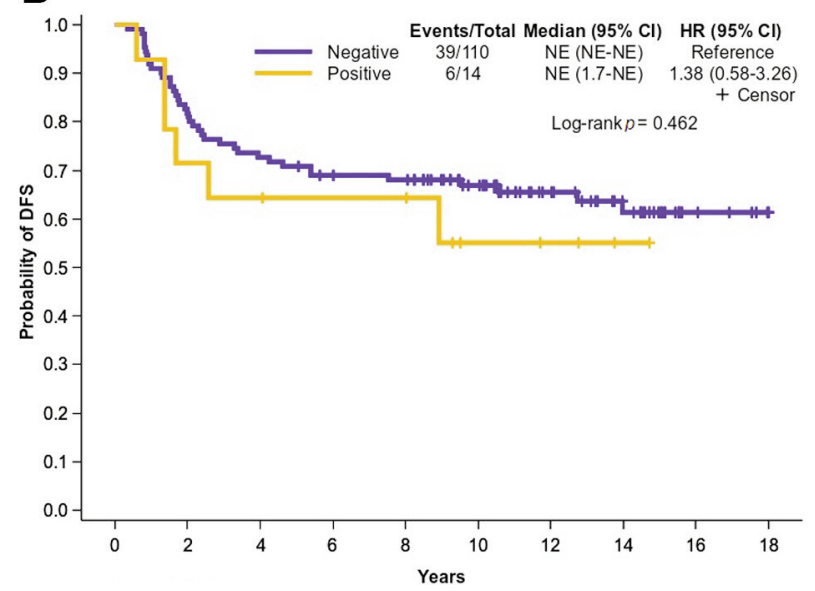

Figure 4. Kaplan-Meier curves based on human proviral integration site for Moloney murine leukemia virus-1 (PIM1) expression with respect to overall (OS) (A) and disease-free (DFS) (B) survival for patients with basal-like tumors. CI: Confidence intervaI; HR: hazard ratio; NE: not estimable.

positive, a percentage in line with other studies $(11,40)$. We evaluated the possible associations between $A R$ expression and selected clinicopathological features. The only significant association found pertained to menopausal status. In particular, the AR-positive rate was significantly higher in postmenopausal women, in agreement with results of a previous study (41). Another important clinicopathological characteristic which is also mentioned in previous published data is that a marginally higher percentage of basal-like tumors was found in AR-negative [79/87 (91.9\%)] than in AR-positive [45/54 (84.9\%)] cases (42).

Furthermore, we investigated the prognostic role of $A R$ expression in this cohort of patients. $A R$ expression did not show prognostic significance in terms of OS. Similarly, no prognostic significance was observed for DFS among the patients with early-stage TNBC. $A R$ expression was further 
evaluated in a subgroup of basal-like tumors in patients with early stage TNBC but no prognostic significance was found for OS and DFS.

With respect to AR expression and survival outcomes, our results are consistent with the conflicting evidence about the prognostic role of AR in TNBC (43). In a recent review and meta-analysis, $\mathrm{Xu}$ et al. extracted and statistically analyzed data from various studies on AR prognostic significance in TNBC and concluded that there was no correlation of AR status with any primary (OS or DFS) or secondary end point (distant DFS or recurrence-free survival) (44). Interestingly, a recent multi-institutional study revealed population-specific differences in prognostic patterns of AR positivity (45). In a study that compared AR expression between White women and African American women, the latter showed lower expression of AR (46). Both studies indicate that discrepancies in results might be attributed to different ethnic or racial characteristics.

In a smaller cohort of the studied patients with TNBC $(n=31)$, we compared AR protein expression as assessed by immunohistochemistry with RT-qPCR results for $A R$ mRNA expression and found significant correlation (Fisher's $p=0.001)$. Despite the limited number of samples, we therefore suggest that RT-qPCR assay may successfully be used for the evaluation of $A R$ expression in TNBC tumors.

We also evaluated the expression of PIMI in this cohort of patients with TNBC based on previous evidence that PIM1 plays a crucial role in TNBC biology (24). According to our results, only a small number of patients was found to be positive for PIMI expression (10.4\%) and all of these had basal-like TNBC tumors, consistent with previous data which indicate increased PIMI expression in these breast cancer tumors (26). In terms of prognosis, no significant correlation was found between PIMI expression and OS or DFS either in the entire cohort or those with early-stage disease. On the contrary, according to published data, PIMI was a factor of poor prognosis in terms of diminished recurrence-free and distant metastasis-free survival in patients with hormone receptor-negative tumors and indirectly through its implication in c-MYC activity (25). Further studies on TNBC should clarify its prognostic role. Many studies based on PIMI functions indicate that PIMI might serve as a novel promising therapeutic target (23). PIM1 inhibition in mouse models was already shown to have no significant effects on growth and reproduction, and in combination with other chemotherapeutic regimens enhanced chemosensitivity $(25,26)$, further enhancing the potential of PIM1 as a new targeted biomarker.

Based on previous evidence on PCa, PIM1 kinases phosphorylate AR, thus regulating its transcriptional activity, independently of androgens. This mechanism seems to play a crucial role during androgen deprivation therapy, thus cotargeting of AR and PIM1 could prove to be a promising therapeutic approach for resistant PCa (27). In our study, seven patients out of $141(5.0 \%)$ carried tumors with positive expression of both $A R$ and PIM1. However, since the number of these patients was very small, we cannot provide any evidence on these potential interacting partners in TNBC and therefore we suggest that extensive research should investigate their simultaneous activity, especially during therapy.

Of note, many discrepancies between the results of various studies regarding the prognosis can be attributed to staining and scoring methods, different AR antibodies used, small sample sizes and heterogeneous patient cohorts (39). An important limitation of our study was that $A R$ and PIMI expression was tested on formalin-fixed paraffin-embedded tumor samples that are in most cases of poor RNA quality, as verified by the exclusion of 50 samples. We thus suggest further analysis of $A R$ and PIMI expression in fresh frozen tissues of patients with TNBC.

There is still an unfilled gap in therapeutic options for TNBC since chemotherapy is the mainstay of treatment following surgery. Taking into consideration that patients with TNBC have unique molecular signatures, the discovery of novel biomarkers is important for molecular targeted therapies. With this in mind, in the present study, we studied $A R$ and PIMI expression in TNBC, based on: a) the fact that therapies targeting $A R$ expression are now being validated in patients with TNBC, b) evidence showing that PIM1 plays a crucial role in TNBC biology, and c) interactions between AR and PIM1 play a crucial role during androgen deprivation therapy and thus cotargeting of AR and PIM1 might improve therapeutic effects. Our results indicate that co-expression of these biomarkers exists only in a small percentage of cases of TNBC. The implications of this finding in the therapeutic management of patients with TNBC should be investigated in larger patient cohorts.

\section{Conclusion}

AR expression defines a subgroup of TNBC that could benefit from AR-targeted therapies, thus the identification of AR levels in these patients is crucial. We suggest that further clinical trials based on validated assays should be held to provide reliable data correlated with the prognostic significance of AR in TNBC and that AR expression based on validated assays clearly discriminate patients with ARpositive TNBC from those with AR-QNBC and thus, contribute to clinician's therapeutic decisions. Furthermore, we suggest that extensive clinical trials should be carried out encompassing large cohorts of patients with TNBC to further test the utility of PIMI as a potential biomarker by providing additional data correlated with its diagnostic and prognostic significance. 


\section{Conflicts of Interest}

There are no conflicts of interest to declare for all Authors in regard to this study.

\section{Authors' Contributions}

Conceptualization: EL, GF and VK. Methodology EL, VK, AN and AS. Validation: EL, AN and AS. Formal analysis: GAK. Investigation: AN and AS. Resources: FZ, DP, GP, CC, HG, CM, CP, PK, GA and GF. Data curation: AN and AS. Writing - Original Draft: AN and EL. Writing - Review and editing: All Authors. Supervision: EL, VK and GF. Funding Acquisition: EL, GF and VK.

\section{Acknowledgements}

The Authors are indebted to all patients and their families for their trust and participation in the Hellenic Cooperative Oncology Group trials and for the provision of biological material for research purposes. The Authors apologize to the main investigators whose work was not referenced due to space limitation.

This study was supported by an internal Hellenic Cooperative Oncology Group (HeCOG) translational research grant (HE TRANS_BR). The funders played no role in study design, data collection and analysis, decision to publish, or preparation of the manuscript. This study was also supported by THALES, a research project by the Greek General Secretariat for Research and Technology, granted to Prof. G. Fountzilas (grant ID by the Research Committee, Aristotle University of Thessaloniki: 85355). This study has also been financially supported by the European Union and Greek national funds through the Operational Program Competitiveness, Entrepreneurship and Innovation, under the call RESEARCH CREATE - INNOVATE (project code: T1RCI-02935).

\section{References}

1 Bianchini G, Balko JM, Mayer IA, Sanders ME and Gianni L: Triple-negative breast cancer: Challenges and opportunities of a heterogeneous disease. Nat Rev Clin Oncol 13(11): 674-690, 2016. PMID: 27184417. DOI: 10.1038/nrclinonc.2016.66

2 Dent R, Trudeau M, Pritchard KI, Hanna WM, Kahn HK, Sawka CA, Lickley LA, Rawlinson E, Sun P and Narod SA: Triplenegative breast cancer: Clinical features and patterns of recurrence. Clin Cancer Res 13(15): 4429-4434, 2007. PMID: 17671126. DOI: 10.1158/1078-0432.CCR-06-3045.

3 Lehmann BD, Bauer JA, Chen X, Sanders ME, Chakravarthy $\mathrm{AB}$, Shyr Y and Pietenpol JA: Identification of human triplenegative breast cancer subtypes and preclinical models for selection of targeted therapies. J Clin Invest 121(7): 2750-2767, 2011. PMID: 21633166. DOI: $10.1172 /$ JCI45014

4 Huang M, O'Shaughnessy J, Zhao J, Haiderali A, Cortés J, Ramsey SD, Briggs A, Hu P, Karantza V, Aktan G, Qi CZ, Gu C, Xie J, Yuan M, Cook J, Untch M, Schmid P and Fasching PA: Association of pathologic complete response with long-term survival outcomes in triple-negative breast cancer: A metaanalysis. Cancer Res 80(24): 5427-5434, 2020. PMID: 32928917. DOI: 10.1158/0008-5472.CAN-20-1792

5 Liedtke C, Mazouni C, Hess KR, André F, Tordai A, Mejia JA, Symmans WF, Gonzalez-Angulo AM, Hennessy B, Green M,
Cristofanilli M, Hortobagyi GN and Pusztai L: Response to neoadjuvant therapy and long-term survival in patients with triple-negative breast cancer. J Clin Oncol 26(8): 1275-1281, 2008. PMID: 18250347. DOI: 10.1200/JCO.2007.14.4147

6 Denkert C, Liedtke C, Tutt A and von Minckwitz G: Molecular alterations in triple-negative breast cancer-the road to new treatment strategies. Lancet 389(10087): 2430-2442, 2017. PMID: 27939063. DOI: 10.1016/S0140-6736(16)32454-0

7 Vagia E, Mahalingam D and Cristofanilli M: The landscape of targeted therapies in TNBC. Cancers 12(4): 916, 2020. PMID: 32276534. DOI: $10.3390 /$ cancers 12040916

8 Rahim B and O'Regan R: AR signaling in breast cancer. Cancers 9(3): 21, 2017. PMID: 28245550. DOI: 10.3390/ cancers 9030021

9 Gerratana L, Basile D, Buono G, De Placido S, Giuliano M, Minichillo S, Coinu A, Martorana F, De Santo I, Del Mastro L, De Laurentiis M, Puglisi F and Arpino G: Androgen receptor in triple-negative breast cancer: A potential target for the targetless subtype. Cancer Treat Rev 68: 102-110, 2018. PMID: 29940524. DOI: $10.1016 /$ j.ctrv.2018.06.005

10 Pietri E, Conteduca V, Andreis D, Massa I, Melegari E, Sarti S, Cecconetto L, Schirone A, Bravaccini S, Serra P, Fedeli A, Maltoni R, Amadori D, De Giorgi U and Rocca A: Androgen receptor signaling pathways as a target for breast cancer treatment. Endocr Relat Cancer 23(10): R485-R498, 2016. PMID: 27528625. DOI: 10.1530/ERC-16-0190

11 Wang C, Pan B, Zhu H, Zhou Y, Mao F, Lin Y, Xu Q and Sun Q: Prognostic value of androgen receptor in triple-negative breast cancer: A meta-analysis. Oncotarget 7(29): 46482-46491, 2016. PMID: 27374089. DOI: 10.18632/oncotarget.10208

12 Bozovic-Spasojevic I, Zardavas D, Brohee S, Ameye L, Fumagalli D, Ades F, De Azambuja E, Bareche Y, Piccart M, Paesmans M and Sotiriou C: The prognostic role of androgen receptor in patients with early-stage breast cancer: A meta-analysis of clinical and gene expression data. Clin Cancer Res 23(11): 2702-2712, 2017. PMID: 28151718. DOI: 10.1158/1078-0432.CCR-16-0979

13 Choi JE, Kang SH, Lee SJ and Bae YK: Androgen receptor expression predicts decreased survival in early stage triple-negative breast cancer. Ann Surg Oncol 22(1): 82-89, 2015. PMID: 25145503. DOI: https://doi.org/10.1245/s10434-014-3984-z

14 Dieci MV, Tsvetkova V, Griguolo G, Miglietta F, Mantiero M, Tasca G, Cumerlato E, Giorgi CA, Giarratano T, Faggioni G, Falci C, Vernaci G, Menichetti A, Mioranza E, Liso E Di, Frezzini S, Saibene T, Orvieto E and Guarneri V: Androgen receptor expression and association with distant disease-free survival in triple-negative breast cancer: Analysis of 263 patients treated with standard therapy for stage I-III disease. Front Oncol 9: 452, 2019. PMID: 31245286. DOI: 10.3389/fonc. 2019.00452

15 Sunar V, Dogan HT, Sarici F, Ates O, Akin S, Baspinar B, Aksoy $\mathrm{S}$ and Altundag K: Association between androgen receptor status and prognosis in triple-negative breast cancer. J BUON 23(5): 1325-1330, 2018, PMID: 30570854.

16 Kraby MR, Valla M, Opdahl S, Haugen OA, Sawicka JE, Engstrøm MJ and Bofin AM: The prognostic value of androgen receptors in breast cancer subtypes. Breast Cancer Res Treat 172(2): 283-296, 2018. PMID: 30109519. DOI: 10.1007/s10549-018-4904-x

17 Salvi S, Bonafè $M$ and Bravaccini S: Androgen receptor in breast cancer: A wolf in sheep's clothing? A lesson from prostate cancer. Semin Cancer Biol 60: 132-137, 2020. PMID: 31002873. DOI: 10.1016/j.semcancer.2019.04.002 
18 Nawijn MC, Alendar A and Berns A: For better or for worse: the role of Pim oncogenes in tumorigenesis. Nat Rev Cancer 11(1): 23-34, 2011. PMID: 21150935. DOI: 10.1038/nrc2986

19 Magnuson NS, Wang Z, Ding G and Reeves R: Why target PIM1 for cancer diagnosis and treatment? Futur Oncol 6(9): 1461-1478, 2010. PMID: 20919829. DOI: 10.2217/fon.10.106

20 Mondello P, Cuzzocrea S and Mian M: Pim kinases in hematological malignancies: Where are we now and where are we going? J Hematol Oncol 7: 95, 2020. PMID: 25491234. DOI: $10.1186 / \mathrm{s} 13045-014-0095-\mathrm{Z}$

21 Alvarado Y, Giles FJ and Swords RT. The PIM kinases in hematological cancers. Expert Rev Hematol 5(1): 81-96, 2012. PMID: 22272708. DOI: 10.1586/ehm.11.69

22 Bellon M, Lu L and Nicot C: Constitutive activation of PIM1 kinase is a therapeutic target for adult T-cell leukemia. Blood 127(20): 2439-2450, 2016. PMID: 26813676. DOI: 10.1182/blood2015-11-685032

23 Panchal NK and Sabina EP: A serine/threonine protein PIM kinase as a biomarker of cancer and a target for anti-tumor therapy. Life Sci 15(255): 117866, 2020. PMID: 32479955. DOI: 10.1016/j.lfs.2020.117866.

24 Chen J and Tang G: PIM1 kinase: A potential biomarker of triple-negative breast cancer. Onco Targets Ther 12: 6267-6273, 2019. PMID: 31496730. DOI: 10.2147/OTT.S212752

25 Horiuchi D, Camarda R, Zhou AY, Yau C, Momcilovic O, Balakrishnan S, Corella AN, Eyob H, Kessenbrock K, Lawson DA, Marsh LA, Anderton BN, Rohrberg J, Kunder R, Bazarov A V., Yaswen P, McManus MT, Rugo HS, Werb Z and Goga A: PIM1 kinase inhibition as a targeted therapy against triple-negative breast tumors with elevated MYC expression. Nat Med 22(11): 13211329, 2016. PMID: 27775705. DOI: 10.1038/nm.4213

26 Brasó-Maristany F, Filosto S, Catchpole S, Marlow R, Quist J, Francesch domenech E, Plumb DA, Zakka L, Gazinska P, Liccardi G, Meier P, Gris-oliver A, Chon M, Cheang U, Perdrixrosell A, Shafat M, Noël E, Patel N, Mceachern K, Scaltriti M, Castel P, Noor F, Buus R, Mathew S, Watkins J, Serra V and Marra P: PIM1 kinase regulates cell death, tumour growth and chemotherapy in TNBC. Nat Med 22(11): 1303-1313, 2017. PMID: 27775704. DOI: 10.1038/nm.4198.PIM1

27 Luszczak S, Kumar C, Sathyadevan VK, Simpson BS, Gately KA, Whitaker HC and Heavey S: PIM kinase inhibition: Cotargeted therapeutic approaches in prostate cancer. Signal Transduct Target Ther 5(1): 7, 2020. PMID: 32296034. DOI: 10.1038/s41392-020-0109-y

28 Strati A, Zavridou M, Bournakis E, Mastoraki S and Lianidou E: Expression pattern of androgen receptors: AR-v7 and AR567 es, in circulating tumor cells and paired plasma-derived extracellular vesicles in metastatic castration-resistant prostate cancer. Analyst 144(22): 6671-6680, 2019. PMID: 31596277. DOI: $10.1039 / \mathrm{c} 9 \mathrm{an} 00999 \mathrm{j}$

29 Markou A, Tzanikou E, Strati A, Zavridou M, Mastoraki S, Bournakis E and Lianidou E: PIM1 is overexpressed at a high frequency in circulating tumor cells from metastatic castration resistant prostate cancer patients. Cancers 12(5): E1188, 2020. PMID: 32397108. DOI: 10.3390/cancers12051188

30 Fountzilas G, Skarlos D, Dafni U, Gogas H, Briasoulis E, Pectasides D, Papadimitriou C, Markopoulos C, Polychronis A, Kalofonos HP, Siafaka V, Kosmidis P, Timotheadou E, Tsavdaridis D, Bafaloukos D, Papakostas P, Razis E, Makrantonakis P, Aravantinos G and Dimopoulos AM: Postoperative dose-dense sequential chemotherapy with epirubicin, followed by CMF with or without paclitaxel, in patients with high-risk operable breast cancer: a randomized phase III study conducted by the Hellenic Cooperative Oncology Group. Ann Oncol 16(11): 1762-1771, 2005. PMID: 16148021. DOI: 10.1093/annonc/mdi366

31 Gogas H, Dafni U, Karina M, Papadimitriou C, Batistatou A, Bobos M, Kalofonos HP, Eleftheraki AG, Timotheadou E, Bafaloukos D, Christodoulou C, Markopoulos C, Briasoulis E, Papakostas P, Samantas E, Kosmidis P, Stathopoulos GP, Karanikiotis C and Pectasides and Fountzilas G: Postoperative dose-dense sequential versus concomitant administration of epirubicin and paclitaxel in patients with node-positive breast cancer: 5-Year results of the Hellenic Cooperative Oncology Group HE 10/00 phase III Trial. Breast Cancer Res Treat 132(2): 609-619, 2012. PMID: 22187126. DOI: 10.1007/s10549-011-1913-4

32 Fountzilas G, Dafni U, Papadimitriou C, Timotheadou E, Gogas H, Eleftheraki AG, Xanthakis I, Christodoulou C, Koutras A, Papandreou CN, Papakostas P, Miliaras S, Markopoulos C, Dimitrakakis C, Korantzopoulos P, Karanikiotis C, Bafaloukos D, Kosmidis P, Samantas E, Varthalitis I, Pavlidis N, Pectasides $\mathrm{D}$ and Dimopoulos MA: Dose-dense sequential adjuvant chemotherapy followed, as indicated, by trastuzumab for one year in patients with early breast cancer: First report at 5-year median follow-up of a Hellenic Cooperative Oncology Group randomized phase III trial. BMC Cancer 14: 515, 2014. PMID: 25026897. DOI: $10.1186 / 1471-2407-14-515$

33 Papadimitriou CA, Papakostas P, Timotheadou E, Aravantinos G, and Bamias A and Fountzilas G: Adjuvant dose-dense sequential chemotherapy with epirubicin, CMF and weekly paclitaxel in patients with resected high-risk breast cancer: A Hellenic Cooperative Oncology Group (HeCOG) study. Cancer Invest 26(5): 491-498, 2008. PMID: 18568771. DOI: 10.1080/07357900 701829785

34 Fountzilas G, Pectasides D, Christodoulou C, Timotheadou E, Economopoulos T, Papakostas P, Papadimitriou C, Gogas H, Efstratiou I and Skarlos D: Adjuvant dose-dense sequential chemotherapy with epirubicin, $\mathrm{CMF}$, and weekly docetaxel is feasible and safe in patients with operable breast cancer. Med Oncol 23(4): 479-488, 2006. PMID: 17303906. DOI: 10.1385/MO:23:4:479

35 Livak KJ and Schmittgen TD: Analysis of relative gene expression data using real-time quantitative PCR and the 2(Delta Delta C(T)) Method. Methods 25(4): 402-408, 2001. PMID: 11846609. DOI: 10.1006/meth.2001.1262

36 Hon JDC, Singh B, Sahin A, Du G, Wang J, Wang VY, Deng FM, Zhang DY, Monaco ME and Lee P: Breast cancer molecular subtypes: From TNBC to QNBC. Am J Cancer Res 6(9): 18641872, 2016. PMID: 27725895.

37 Jovanović B, Mayer IA, Mayer EL, Abramson VG, Bardia A, Sanders ME, Kuba MG, Estrada MV, Beeler JS, Shaver TM, Johnson KC, Sanchez V, Rosenbluth JM, Dillon PM, ForeroTorres A, Chang JC, Meszoely IM, Grau AM, Lehmann BD, Shyr Y, Sheng Q, Chen SC, Arteaga CL and Pietenpol JA: A randomized phase II neoadjuvant study of cisplatin, paclitaxel with, or without everolimus in patients with stage II/III triplenegative breast cancer (TNBC): Responses and long-term outcome correlated with increased frequency of DNA damage response gene mutations, TNBC subtype, AR status, and Ki67. Clin Cancer Res 23(15): 4035-4045, 2017. PMID: 28270498. DOI: $10.1158 / 1078-0432 . C C R-16-3055$ 
38 Saini G, Bhattarai S, Gogineni K and Aneja R: Quadruple-negative breast cancer: An uneven playing field. JCO Glob Oncol 6: 233237, 2020. PMID: 32073910 . DOI: 10.1200/jgo.19.00366

39 Angajala A, Mothershed E, Davis MB, Tripathi S, He Q, Bedi D, Dean-Colomb W and Yates C: Quadruple-negative breast cancers (QNBC) demonstrate subtype consistency among primary and recurrent or metastatic breast cancer. Trans1 Oncol 12(3): 493-501, 2019. PMID: 30594038. DOI: 10.1016/j.tranon.2018.11.008

40 Ricciardelli C, Bianco-Miotto T, Jindal S, Butler LM, Leung S, McNeil CM, O'Toole SA, Ebrahimie E, Millar EKA, Sakko AJ, Ruiz AI, Vowler SL, Huntsman DG, Birrell SN, Sutherland RL, Palmieri C, Hickey TE and Tilley WD: The magnitude of androgen receptor positivity in breast cancer is critical for reliable prediction of disease outcome. Clin Cancer Res 24(10): 2328-2341, 2018. PMID: 29514843. DOI: 10.1158/10780432.CCR-17-1199

41 Jongen L, Floris G, Wildiers H, Claessens F, Richard F, Laenen A, Desmedt C, Ardui J, Punie K, Smeets A, Berteloot P, Vergote I and Neven P: Tumor characteristics and outcome by androgen receptor expression in triple-negative breast cancer patients treated with neo-adjuvant chemotherapy. Breast Cancer Res Treat 176(3): 699-708, 2019, 2019. PMID: 31106385. DOI: 10.1007/s10549-019-05252-6

42 Burstein MD, Tsimelzon A, Poage GM, Covington KR, Fuqua SAW, Savage MI, Osborne CK, Susan G, Chang JC, Mills GB, Lau CC and Brown PH: Comprehensive genomic analysis identifies novel subtypes and targets of triple-negative breast cancer. Clin Cancer Res 21(7): 1688-1698, 2015. PMID: 25208879. DOI: $10.1158 / 1078-0432$.CCR-14-0432

43 Venema CM, Bense RD, Steenbruggen TG, Nienhuis HH, Qiu SQ, van Kruchten M, Brown M, Tamimi RM, Hospers GAP, Schröder CP, Fehrmann RSN and de Vries EGE: Consideration of breast cancer subtype in targeting the androgen receptor. Pharmacol Ther 200: 135-147, 2019. PMID: 31077689. DOI: 10.1016/j.pharmthera.2019.05.005
44 Xu M, Yuan Y, Yan P, Jiang J, Ma P, Niu X, Ma S, Cai H and Yang K: Prognostic significance of androgen receptor expression in triple-negative breast cancer: A systematic review and metaanalysis. Clin Breast Cancer 20(4): e385-e396, 2020. PMID: 32139270. DOI: 10.1016/j.clbc.2020.01.002

45 Bhattarai S, Klimov S, Mittal K, Krishnamurti U, Li XB, OpreaIlies G, Wetherilt CS, Riaz A, Aleskandarany MA, Green AR, Ellis IO, Cantuaria G, Gupta M, Manne U, Agboola J, Baskovich B, Janssen EAM, Callagy G, Walsh EM, Mehta A, Dogra A, Shet T, Gajaria P, Traina T, Nggada HA, Omonisi A, Ahmed SA, Rakha EA, Rida P and Aneja R: Prognostic role of androgen receptor in triple-negative breast cancer: A multiinstitutional study. Cancers 11(7): 1-9, 2019. PMID: 31319547. DOI: $10.3390 /$ cancers 11070995

46 Davis M, Tripathi S, Hughley R, He Q, Bae S, Karanam B, Martini R, Newman L, Colomb W, Grizzle W and Yates C: AR negative triple-negative or "quadruple-negative" breast cancers in African American women have an enriched basal and immune signature. PLoS One 13(6): e0196909, 2018. PMID: 29912871 DOI: 10.1371/journal.pone.0196909.t002
Received December 7, 2020

Revised January 11, 2021

Accepted January 13, 2021 